\title{
REVIEW
}

\section{Psoriatic Arthritis: The Influence of Co-morbidities on Drug Choice}

Sneha Patel $\cdot$ Anand Kumthekar (10)

Received: August 3, 2021 / Accepted: September 28, 2021 / Published online: November 19, 2021

(C) The Author(s) 2021

\begin{abstract}
Psoriatic arthritis (PsA) is associated with a higher burden of co-morbidities such as obesity, cardiovascular disease, non-alcoholic fatty liver disease, inflammatory eye disease, inflammatory bowel disease, skin cancer and depression compared to the general population. In the last 20 years, the therapeutic options for PsA have increased exponentially with the availability of tumor necrosis factor-alpha (TNF) inhibitors, interleukin (IL)-17 inhibitors, IL-12/23 inhibitors and Janus kinases/signal transducer and
\end{abstract}

S. Patel

Rheumatology, Acclaim Physicians/JPS Hospital, Fort Worth, TX, USA

A. Kumthekar $(\bowtie)$

Division of Rheumatology, Department of

Medicine, Montefiore Medical Center/Albert

Einstein College of Medicine, New York, NY, USA

e-mail: anakumth@montefiore.org activator of transcription proteins (JAK/STAT) inhibitors. The articular and extra-articular manifestations of PsA usually dictate the treatment choice but important consideration must be given to the corresponding co-morbidities while deciding the drug therapy due to associated safety profile, effect on disease activity, etc. This review provides a comprehensive review of common co-morbidities in PsA and how they can influence treatment choices.

Keywords: Psoriatic arthritis; Co-morbidities; Drug therapy 


\section{Key Summary Points}

Psoriatic arthritis patients have a high burden of co-morbidities such as obesity, cardiovascular disease, etc., which should be considered while making therapeutic choices

Overall cardiovascular risk is increased in patients with PsA, and there is evidence to suggest that treatment with TNFi can improve cardiovascular outcomes

Although rare, IL-17 inhibition should be considered with caution if there is associated IBD with PsA due to low but reported risk of IBD flares

There is no clear association between most malignancies and csDMARD/bDMARD but a shared decision should be made before starting therapy

Obesity can increase risk of NAFLD and methotrexate toxicity and reduce TNFi efficacy, but a higher BMI has not been associated with a poor treatment response with IL-17A inhibitors, IL12/23 inhibitors or JAK/STAT inhibitors.

The risk of liver disease and renal disease with bDMARD use appears low

\section{INTRODUCTION}

Psoriatic arthritis (PsA) is a complex heterogenous condition which shares clinical, genetic and etiopathogenic features with other forms of spondyloarthritis (SpA). PsA affects around $10-30 \%$ of patients with psoriasis (PsO), and management of PsA relies on careful evaluation of disease activity, extra-articular features and associated co-morbid conditions [1]. Prevalent co-morbidities in PsA include metabolic syndrome (hypertension, diabetes mellitus, hyperlipidemia), cardiovascular disease, obesity, nonalcoholic fatty liver disease (NAFLD), malignancy, depression and extra-articular manifestations: psoriasis, inflammatory eye disease and inflammatory bowel disease (IBD) [2-5]. A large proportion of PsA patients have at least one comorbidity, and around $40 \%$ of patients can have three or more co-morbidities $[6,7]$. Therapies can directly and indirectly impact co-morbid conditions despite having anticipated goals of improving PsA disease activity.

PsA treatment is focused on reducing inflammation and disease progression by utilizing non-steroidal anti-inflammatories (NSAID), glucocorticosteroids (GCs), conventional synthetic disease-modifying anti-rheumatic drugs (csDMARD), biologic DMARDs (bDMARDs) and targeted synthetic DMARDs (tsDMARDs). The therapeutic options for PsA have increased substantially over the years with available bDMARD therapies targeting tumor necrosis factor alfa (TNF- $\alpha$ ), interleukin (IL)17A, IL-12/23 and tsDMARD therapies targeting Janus kinases/signal transducer and activator of transcription proteins (JAK/STAT). Non-pharmacologic treatment includes physical therapy, smoking cessation, weight loss, behavioral therapy and exercise, which are extremely crucial [8].

The 2018 American College of Rheumatology (ACR)/National Psoriasis Foundation (NPF) guidelines for the treatment of PsA as well as the updated 2019 European Alliance of Associations for Rheumatology (EULAR) recommendations for the management of PsA provide an excellent framework regarding treatment options for PsA $[9,10]$. When applying to individual clinical care, all recommendations should be based on a risk-benefit assessment for the patient and a shared decision. It is imperative to consider existing co-morbidities when choosing drug therapy for PsA as co-morbidities can influence the treatment choice, disease activity and outcomes.

This narrative provides a review of the burden of the prevalent associated conditions in PsA and how the drug therapies for PsA affect these co-morbidities and vice versa. This article is based on previously conducted studies and does not contain any studies with human 
participants or animals performed by any of the authors.

\section{ASSOCIATED CO-MORBIDITIES}

\section{Cardiovascular Disease}

PsA is known to increase the risk of cardiovascular disease (CVD) and major adverse cardiovascular events (MACE) compared to the general population $[11,12]$. Oxidative stress and subsequent pro-inflammatory cytokine production, such as tumor necrosis factor alpha (TNF $\alpha$ ), interleukin (IL) 1Beta, IL-6, IL-1 and IL17 , are a few of the mechanisms implicated in plaque development within PsA [11]. Certain therapies can impact cardiovascular risk although PsA patients are already at an increased risk, secondary to traditional risk factors: age, smoking history, hyperlipidemia, hypertension and diabetes [13].

Non-steroidal anti-inflammatory drugs (NSAIDs) are the first-line therapy in patients with mild disease, predominant enthesitis and axial spondylitis [10, 14]. Cyclooxygenase (COX) inhibition, specifically COX-2 inhibition, increases risk of atherogenesis, hypertension, arrythmias and heart failure. Certain nonselective COX inhibitors, such as naproxen, carry less cardiovascular risk compared to COX2 inhibitors [15].

Corticosteroids are used in most immunerelated rheumatic diseases to control inflammation temporarily. In psoriatic arthritis, corticosteroids are used with caution secondary to concern of cutaneous flare; however, studies have shown that moderate doses of corticosteroids (methylprednisolone $<16 \mathrm{mg}$ /day) were not associated with erythroderma, severe pustular psoriasis or severe flares [16]. Local glucocorticoid injections can be used for mono/ oligoarthritis and enthesitis [10]. There is a concern for $\mathrm{CV}$ risk in PsA patients on corticosteroids in rheumatic disease. A cohort study of CVD patients with and without PsA found that treatment with corticosteroids was associated with marginal increased risk of CVD and MACE with an incidence rate (IR) of 33.6/1000 person-years (PYs) (CI 13.5-69.2) compared to those on bDMARDs and csDMARDs, which had an IR of 15.6/1000PY (CI 13.3-18.1) [17].

The risk of CVD with CsDMARD and bDMARD use in PsA appears to be low based on several studies. One study revealed that the risk of MACE in PsA patients on no DMARD therapy (methotrexate, sulfasalazine, leflunomide, TNF inhibitors [TNFi]) was high with a hazard ratio (HR) of 1.24 (confidence interval [CI] 1.03-1.49) compared to 1.17 (CI 0.95-1.46) for PsA patients on DMARDs [11]. A systematic review of PsA/PsO studies concluded that systemic therapy (TNFi, methotrexate, NSAIDs and corticosteroids) was associated with a significant decrease in risk of all CV events in PsA or PsO (RR, 0.75; 95\% CI 0.63-0.91) [18]. Although methotrexate has also been shown to improve endothelial function, low-dose methotrexate failed to show reduction in pro-inflammatory cardiovascular cytokines $[19,20]$. In a longitudinal cohort study, patients with severe PsO on methotrexate had an IR of 4.16 per 1000 patient-years for $\mathrm{CV}$ events but reduced the risk of events relative to other therapies with HR 0.53 (CI 0.34-0.83) [21]. Overall, methotrexate continues to be a useful therapy in uncontrolled PsA and is recommended relatively first line in polyarthritis based on EULAR recommendations and for mild disease based on ACR recommendations [10, 14].

The bDMARDs, including TNFi, anti-IL-17, anti-IL-12/23, anti-IL-23 and JAK/STAT inhibitors, can be used in patients naive to treatment, resistant to initial treatment or with specific comorbidities [10, 14]. While EULAR considers bDMARDs as third line, ACR recommends TNFi in active PsA naïve to treatment [10, 14]. Multiple cohort studies suggest that bDMARDs may have a cardio-protective effect in PsO patients, with an almost 50\% reduction in the rate of myocardial infarction [22, 23]. TNF-mediated inflammation has been thought to play a role in CV disease [24]. In a cohort study of $>60,000$ PsA patients treated with different bDMARDs and csDMARDs, IR for myocardial infarction was lowest for patients on TNFi (1.4 per 1000 PY) [25]. In a meta-analysis of 5 studies of 50,000 PsA patients, TNFi reduced risk of cardiovascular events compared to placebo and reduced incidence of myocardial infarction 
Table 1 Immunomodulators in PsA with specific co-morbidities

\begin{tabular}{llll}
\hline Co-morbidity & csDMARD & bDMARD & tsDMARD \\
\hline Psoriasis & Mtx, Apr & TNFi, Il-17i, ${ }^{*}$ IL 12/23i, IL-23i & ${ }^{*}$ JAKi \\
Inflammatory bowel disease & SSZ, Mtx & TNFi, ${ }^{*}$ Il-17i, IL 12/23i & ${ }^{*}$ JAKi \\
Uveitis & Mtx, SSZ & ${ }^{\$}$ TNFi, ${ }^{*}$ Il-17 i, ${ }^{\wedge}$ IL 12/23i & \\
Cardiovascular disease & Mtx, Lef, SSZ & TNFi, Il-17i, ${ }^{*}$ IL 12/23i, IL-23i & - \\
Malignancy & ${ }^{*}$ Mtx & ${ }^{*}$ TNFi, Il-17i, IL 12/23i & - \\
Obesity & Mtx, Lef, SSZ, Apr & TNFi, Il-17i, ${ }^{*}$ IL 12/23i & JAKi \\
Diabetes & Mtx, Lef, SSZ, Apr & TNFi, Il-17i, ${ }^{*}$ IL 12/23i & - \\
Multiple sclerosis & Lef & IL17i, ${ }^{*}$ IL12/23i & - \\
Psychiatric illnesses & Mtx, Lef, SSZ & TNFi, IL 17i, IL 12/23i & - \\
Pregnancy & SSZ & TNFi & - \\
Renal disease & SSZ, ${ }^{+}$Lef, ${ }^{+}$Mtx & TNFi, Il-17i, IL 12/23i, IL-23i & ${ }^{*+}$ JAKi \\
Hepatic disease (non-infectious) & ${ }^{*}$ SSZ, ${ }^{+}$Lef, ${ }^{+}$Mtx & ${ }^{*}$ TNFi, Il-17i, IL 12/23i, IL-23i & ${ }^{*+}$ JAKi \\
\hline
\end{tabular}

csDMARD conventional synthetic disease-modifying anti-rheumatic drugs, bDMARD biologic disease-modifying antirheumatic drugs, tsDMARD targeted synthetic disease-modifying anti-rheumatic drugs, Mtx methotrexate, Lef leflunomide, $S S Z$ sulfasalazine, Apr apremilast, TNFi TNF inhibitors (adalimumab, infliximab, golimumab, certolizumab, etanercept), IL-17i IL-17 inhibitors (secukinumab, ixekizumab), IL-12/23-i IL 12/23 inhibitors (ustekinumab), IL-23i IL 23 inhibitors (guselkumab), JAKi Janus kinase inhibitors (tofacitinib)

* Relatively safe but must be used with caution after a shared decision

${ }^{+}$Dose adjustment required

-Low quality and/or insufficient data

$\$$ Only adalimumab and infliximab

\# Only secukimumab

^Only usetekinumab

compared to individuals on methotrexate alone [26]. In another study with a 5-year follow-up, TNFi reduced risk of cardiovascular events with HR 0.46 (CI 0.22-0.98) [21] (Table 1).

The safety and use of TNFi with advanced heart failure are controversial. TNFi therapies should be used with caution in class III/IV heart failure. In moderate-severe heart failure, stable class III/IV, use of infliximab, independent of inflammatory arthritis, did not improve clinical status. The risk of death from any cause or hospitalization from heart failure was increased in those patients on $10 \mathrm{mg} / \mathrm{kg}$ infliximab dosing [27]. Contrarily, etanercept therapy for 3 months was safe and well tolerated in advanced heart failure [28].
The role of IL-17 inhibition and IL-12/23 inhibition in atherosclerotic disease is still unclear. Based on ACR guidelines, IL-17 inhibition is typically recommended after failure of TNFi therapy [14]. In the CARIMA (Evaluation of Cardiovascular Risk Markers in Psoriasis Patients Treated with Secukinumab) study, flow-mediated dilation (a measure of endothelial function) improved at week 52 of secukinumab use at dose of $300 \mathrm{mg}$ weekly $(+2.1 \%$, CI $0.8-3.3 ; P=0.0022$ ) while this was not seen at week $12(+1.2, P=0.223)$. The $150 \mathrm{mg}$ dose did not reach statistical significance in either group [29]. The pooled exposure-adjusted IR of MACE across MEASURE-1 and MEASURE-2 studies evaluating use of secukinumab in ankylosing spondylitis (AS) was 0.4 events per 
100 patient-years of exposure to secukinumab and 0.3 per 100 patient-years in the secukinumab trial in PsA $[30,31]$. In a 5-year followup of ixekizumab users, MACE ranged from 0.3 to $0.7 / 100$ patient-years [32]. In a cohort of 9071 ustekinumab users, overall MACE events were 6.2 (95\% CI, 4.9-7.8) compared to 6.1 (95\% CI 5.5-6.7) for TNFi [33]. The combined hazard ratio for MACE among ustekinumab initiators was 1.10 (95\% CI, 0.80-1.52) [33]. In another cohort of patients with severe PsO, while methotrexate and TNFi agents were associated with lowered cardiovascular risk, ustekinumab was not (HR 1.52; CI 0.47-4.94) [21]. A meta-analysis of RCTs of patients with PsA and psoriasis did not find any significant difference of MACE or congestive heart failure seen in patients receiving TNFi (adalimumab, certolizumab, etanercept, golimumab, infliximab), anti-Il17 (brodalumab, ixekizumab, secukinumab), anti-IL12/23 (briakinumab, ustekinumab) and antilL23 (guselkumab, risankizumab, tildrakizumab) compared to placebo [34]. Although there does not appear to be an increased MACE with ustekinumab, another meta-analysis found a trend for an increased risk in MACE in patients exposed to an anti-IL $12 / 23$, which was not statistically significant $[33,34]$.

In 2017, tsDMARD tofacitinib was approved for use in PsA; upadacitinib is approved in the European Union. There has been a growing concern surrounding the safety of JAK inhibitors (JAKi) due to reported MACE and venous thromboembolism (VTE). Recent FDA warnings have been placed for increased risk of MACE with JAKi [35]. In one study, although limited to rheumatoid arthritis (RA) patients, the incidence rate of MACE with JAKi use was 0.4 patients with events per 100 patient-years [13]. Baseline age, hypertension and the total cholesterol to high-density lipoprotein (HDL) cholesterol ratio was associated with risk of MACE, and there was increased risk of MACE with elevated sedimentation rate [13]. In a posthoc analysis of 783 PsA patients treated with tofacitinib, increases in all lipid parameters including both LDL and HLD levels with no change in total cholesterol to HDL ratio were noted. Five $(0.6 \%)$ patients of the 783 included had MACE with incidence ratio 0.24 (CI 0.05-0.70), and 2 were fatal [36]. In a phase 3 study evaluating upadacitinib for PsA, one event $(0.5 \%)$ of MACE and VTE was reported, respectively [37]. Thus, caution should be exercised when considering JAKi therapy and a history of VTE or MACE.

PsA inherently increases the risk of cardiovascular disease, and therefore choice of therapeutic agent requires a proper risk assessment based on traditional risk factors and associated co-morbidities. The use of TNFi, IL-17 and IL$12 / 23$ inhibitors does not seem to increase the risk of adverse CV outcomes but JAKi should be used cautiously in patients with higher cardiovascular co-morbidities or VTE.

\section{Malignancy}

The overall incidence of malignancy including non-melanoma skin cancer (NMSC) is increased in patients with severe PsO [38, 39]. The increased risk of cancer with PsA is unclear. The Toronto PsA cohort study of 665 patients reported a malignancy risk of $10.2 \%$, which is similar to that of the general population [40]. Contrarily, in a study of 217 PsA patients, the incidence of overall malignancy, excluding NMSC, was found to be higher with HR ratio of 1.64 (CI 1.03-2.61), and breast cancer had HR of 3.59 with a wide CI (1.22-10.61) [41]. A systematic review of 112 articles did not find an increased risk of cancer in PsA patients [38].

The data regarding malignancy risk with csDMARDs and bDMARDs are unclear. In one study of 248 methotrexate-treated $\mathrm{PsO}$ patients, 10 malignant neoplasms were found; the risk was not higher than that of the general population, and the study found that methotrexate therapy did not contribute to the development of neoplasm [42]. Another study of $>12,000$ $\mathrm{PsO}$ patients found no increased risk for overall or frequently observed malignancies with any duration of treatment with methotrexate [43].

TNFi may increase risk of non-melanoma skin cancers, which is concerning in patients with known active PsO. In an analysis of 6 studies with 123,031 patients, rheumatoid arthritis patients on TNFi therapy had increased 
risk of NMSC with relative risk of 1.28 (CI 1.19-1.38, $P=0.056$ ) [44]. Another study in patients on TNFi showed odds ratio for malignancy of 1.48 (CI $0.71-3.09$ ) and 1.28 (CI 0.39-4.15) when non-melanoma skin cancer was excluded [45]. Bonovas et al. revealed no clear association between TNFi and cancer in a systemic review of a randomized controlled trial (RCT) with an odds ratio of 1.31 (CI 0.89-1.95) [46]. In another study of 618 PsA patients, 296 of whom were on TNFi and 322 on csDMARD, there was no statistically significant association between bDMARDs or csDMARDs and malignancy [47] (Table 1). In the same study, 44 patients had a diagnosis of malignancy; 14 of these patients were on TNFi and 30 were on csDMARDs (azathioprine, methotrexate, leflunomide, sulfasalazine); however, the difference was not statically significant after adjusting for clinical and demographic factors [47]. Data from two large Swedish registries, ARTIC (Anti-Rheumatic Therapy in Sweden [ARTIS]) and DANBIO (Danish biologics registers), also studied the cancer risk in $>8500$ spondyloarthritis patients and found that TNFi was not associated with an increased risk of cancer, including the six most common cancer types [48]. In those with pre-existing history of cancer, there was no increased risk of secondary malignant neoplasms in those on bDMARD (TNFi) use compared to those with nonbDMARD use with HR of 1.11 (CI 0.74-1.67). The HR for death for bDMARD use before primary cancer was 1.20 (CI $0.88-1.63$ ) and HR 1.36 (CI 0.78-2.39) after cancer [49]. Therefore, treatment with certain bDMARDs was not conclusively associated with increased risk of secondary malignancy.

The malignancy risk associated with JAKi is also unclear with a study showing no increased malignancy risk in those on tofacitinib therapy with odds ratio of 1.15 (CI 0.24-5.47) [50, 51]. In another study the incidence ratio of nonNMSC malignancy in RA users on upadacitinib $15 \mathrm{mg}$ was 1.05 (0.66-1.60), which was documented to be in range with the general population [52]. Recent FDA warnings have been issued for increased risk of malignancy with JAKi [35].
The observed rate of malignancies other than NMSC in ustekinumab-treated patients is like that of the general population with standardized incidence ratio 0.98 (CI $0.74-1.39$ ), 0.60/ 100 patient-years (PY) (CI 0.45-0.78) [53]. Follow-up data from the PHOENIX1/2 studies and safety data from the Psoriasis Longitudinal Assessment and Registry demonstrated low or no overall increased risk for malignancy with long-term exposure to ustekinumab [43]. In a 5-year study, patients treated with secukinumab had low malignancy risk with the exposure-adjusted incidence rates of malignancy of 0.85 per 100 patient treatment years (CI 0.74-0.98), equivalent to 204 patients per 23,908 patient treatment years [54]. Similarly, in an analysis of 8228 patients with ixekizumab exposure, malignancy was rarely reported with an IR $<0.8$ [55]. In another 5-year safety follow-up study of 2749 patients with $>4$ years of ixekizumab exposure, rate of NMSC was 0.2/100 patientyears and other malignancy ranged from 0.4 to $0.6 / 100$ patient-years [32]. Although the risk of malignancy with csDMARDs and bDMARDs appears low, a shared decision must be made about the therapeutic choice.

\section{Renal/Hepatic Dysfunction}

Patients with PsA and treated PsO are at an increased risk of liver disease with a $32 \%$ prevalence of liver abnormalities and are twice as likely to develop liver injury, respectively $[56,57]$. PsA and treated PsO are also risk factors for kidney disease with a hazard ratio of 7.60 and 1.19 , respectively, of developing end-stage renal disease [58]. These associations are likely secondary to known risk of metabolic syndrome and concomitant hypertension, obesity and diabetes.

All csDMARDs can potentially elevate transaminases and require regular monitoring. Patients with known hepatotoxicity are at greater risk for developing severe liver injury. Methotrexate is avoided or used with caution in patients with underlying liver disease. Patients with PsA have a greater risk for NAFLD, and preexisting moderate-to-severe hepatic fat deposition and obesity had an adjusted hazard ratio of 
7.69 and 2.68, respectively, for developing elevated and persistent transaminitis [59]. Elevations in liver enzymes occur in $15-50 \%$ of patients treated with low-moderate dose methotrexate, and the incidence of severe hepatotoxicity in methotrexate treated $\mathrm{PsO}$ patients was as high as 23\% [60]. Elevation in liver enzymes is seen in up to $15 \%$ of patients on leflunomide; however, these are usually mild and self-limiting. Again, patients who develop fibrosis appear to have risk factors for fatty liver disease [61]. Compared to rheumatoid arthritis, those with PsO and PsA are thought to be more susceptible to risk of liver disease with methotrexate use [62]. The use of combination leflunomide and methotrexate can increase the risk of silent fibrosis, thought to be influenced by the cumulative dose of leflunomide [63].

Rarely, sulfasalazine can cause significant liver injury, and pathogenesis is thought to be related to a drug allergy or generalized hypersensitivity reaction. This can be induced by sulfonamide allergy or secondary to the 5 -aminosalicyclic acid component of the drug, which can cause idiosyncratic liver injury [61]. Although rare, NSAID use can also cause liver injury with diclofenac and sulindac most reported [61].

TNFi seldom cause liver injury, but cases have been reported of worsening liver enzymes and drug-induced autoimmune hepatitis. One study included 226,555 incident patients with immune-related diseases, and during the median 1.5-year follow-up, there was an increased HR of composite liver disease, cirrhosis and NAFLD/NASH with TNFi agent (HR 1.47 [CI 1.27-1.70]; HR 1.47 [CI 0.96-2.23]; HR 1.53 [CI 1.32-1.77]), respectively [64]. Researchers reviewed cases from the US DILI (Drug-Induced Liver Injury) registry and PubMed of patients on TNFi and found 22 patients with liver injury and positive anti-nuclear/smooth muscle, 15/17 of whom had biopsy with autoimmune features [65]. Although elevated liver enzymes have been seen in tofacitinib use, in both tofacitinib and placebo groups, the incidence of transaminitis was higher in those with hepatic steatosis than in those without hepatic steatosis [66]. Grade 3 elevations in liver enzymes were seen in $2 \%$ or fewer patients in both $15 \mathrm{mg}$ and
$30 \mathrm{mg}$ upadacitinib groups compared to adalimumab [67]. This speaks to the importance of treating underlying co-morbid conditions contributing to fatty liver disease. Apremilast, a tsDMARD targeting phosphodiesterase-4, has not been shown to alter liver enzymes or kidney function in clinical trials [68].

Chronic kidney disease also limits the use of NSAIDs and csDMARDs, particularly methotrexate. NSAIDs cause nephrotoxicity through COX inhibition, with increased risk in those with prior renal disease, cardiovascular risk factors and concomitant nephrotoxic medications, and is influenced by dose and duration of use [69]. Methotrexate in high doses can cause renal toxicity, and recommendations for using low-moderate dose methotrexate depend on glomerular filtration rate (GFR) [70]. Doses $>12 \mathrm{mg} /$ week were associated with a decrease in GFR of 0.25 over 1 year compared to $8-12 \mathrm{mg} /$ week [71]. In an older study of 21 patients who received methotrexate $7.5 \mathrm{mg} /$ week for 2 years, there was an $11 \%$ reduction in creatinine clearance after 6 months with reduction in clearance of methotrexate by $25 \%$ [72]. Extra care should be taken in those at higher risk for lower creatinine clearance including elderly patients and those on nephrotoxic medications. Both leflunomide and sulfasalazine typically do not need dose adjustment based on renal function [73]. TNFi agents have not been associated with renal injury and are safe to use in patients with renal disease [74]. IL-17 inhibition and IL12/23 inhibition have not been associated with liver or kidney dysfunction [68].

\section{Obesity}

Obesity (body mass index $[\mathrm{BMI}] \geq 30 \mathrm{~kg} / \mathrm{m}^{2}$ ) is a state of chronic low-grade inflammation and is a major comorbidity in PsA $[75,76]$. Multiple case control and cohort studies have established that obesity is not only a risk factor for development of PsA but can also affect disease activity and therapeutic choices [77-80]. It is a negative predictor of treatment response for csDMARDs and bDMARDs. Obesity is closely associated with simple steatosis, NAFLD and 
NAFLD-related cirrhosis [81]. Methotrexate does not affect body weight or BMI but it is important to consider the effects of obesity on the liver prior to treatment of PsA with methotrexate. PsA patients have higher burden of liver disease compared to the general population, which is increased with obesity. A cross-sectional study identified the prevalence of NAFLD to be significantly higher in patients with $\mathrm{PsO}$ compared to control (44\% vs. $26 \%$ ) [82]. Similarly, a population-based study of PsO and PsA patients demonstrated a significantly elevated risk of any liver disease (HR 1.37, 1.38), NAFLD (HR 2.23, 2.11) and risk of cirrhosis (HR 2.62, 3.15), respectively [83]. Contrarily, a prospective study of $54 \mathrm{PsO}$ and PsA patients showed mild early fibrosis in $22 \%$ of the cases [84]. Obesity has been categorized as a risk factor for methotrexate-related liver toxicity, and the American Academy of Dermatology (AAD) guidelines proposed a liver biopsy when the cumulative dose approached $1.5 \mathrm{~g}$ [85]. Though there are no specific guidelines for toxicity monitoring in PsA patients on methotrexate from the ACR, liver function tests should be performed every 2-4 weeks for the first 3 months and then every 8-12 weeks [86]. Apremilast has a unique side effect of weight loss, and during the 52-week study period in PsA patients, weight loss $>5 \%$ was observed in $32 \%$ of the study population [87].

Higher BMI can affect the volume of distribution of an administered drug, as well as its elimination, leading to insufficient dosing and limited efficacy [88, 89]. Infliximab and golimumab are the only TNFi routinely administered intravenously in a weight-based dose while other TNFi are usually administered in a fixed dose regimen. TNF- $\alpha$ induces muscle protein breakdown and downregulates the expression of anabolic hormones and growth factors [90]. TNFi suppresses TNF- $\alpha$, and weight gain has been reported in PsO and PsA patients treated with TNFi for 12-48 weeks [91, 92]. Obese patients are at risk of having poor response to TNFi medications [93]. In a prospective cohort study of 135 obese and 135 normal-weight PsA patients treated with TNFi, obese patients were more likely to not achieve and maintain minimal disease activity (MDA)
(HR: 4.90, [95\% CI] 3.04-7.87; $P<0.001$ ) [94]. Data from two large European registries suggest that there was no difference in TNFi doses between the obese and non-obese group, but obesity was associated with less adherence and response to TNFi [95]. In a systematic review with meta-analysis of 54 cohorts with 19,372 patients, obesity was associated with a 60\% higher odds of failing TNFi therapy compared to non-obese and normal BMI patients across all forms of inflammatory immune-mediated diseases including PsA [93]. Ogdie et al. reported that obesity was among the strongest predictors with OR $0.51(0.33-0.81)$ for not achieving Clinical Disease Activity Index (CDAI) remission [96]. Weight loss has been shown to improve disease activity in PsA [97]. In PsA patients treated with TNFi, the OR of achieving MDA was 6.67 with $>10 \%$ weight loss compared to OR 3.75 with $5-10 \%$ weight loss and lower if weight loss is $<5 \%$ [98].

IL $12 / 23$ do not affect muscle breakdown, and the IL-12/IL-23 inhibitor, ustekinumab, was not associated with increased BMI or body weight (mean body weight increase $0.6 \pm 1.1 \mathrm{~kg}$ ) compared with infliximab (mean body weight increase $2.5 \pm 3.3 \mathrm{~kg}$ ) in patients with chronic plaque psoriasis treated over a 7-month period [99]. The dosing for ustekinumab is weight based with the $45-\mathrm{mg}$ dose indicated for patients with body weight $<100 \mathrm{~kg}$, whereas the 90-mg dose for those weighing $>100 \mathrm{~kg}$. A study of 3800 patients with plaque psoriasis treated with ixekizumab and sub-grouped based on body weight did not find any difference in treatment effectiveness based on body weight [100]. Interestingly, Pantano et al. analyzed the effect of BMI on secukinumab response in 100 PsA patients and observed that a higher BMI was associated with lower disease activity score thus suggesting a better response to secukinumab [101]. Pooled data analysis of 710 PsA patients treated with tofacitinib demonstrated that tofacitinib is more effective than placebo, regardless of baseline BMI, but reduced efficacy was observed in patients with baseline $\mathrm{BMI} \geq 35 \mathrm{~kg} / \mathrm{m}^{2}$ [102] (Table 1).

There is no conclusive evidence that any PsA treatment is responsible for a significant 
increase in weight though apremilast can cause weight loss in a certain subset of patients. A higher BMI can have a negative impact on certain treatments such as methotrexate and TNFi but does not affect response to treatment with IL-17A, IL12/23 or JAK/STAT inhibitors.

\section{Diabetes}

Diabetes mellitus (DM) is a prevalent comorbidity in PsA patients worldwide as seen from population-based and cohort studies [103, 104]. The prevalence of DM is higher in North American PsA patients, which is likely related to the higher burden of obesity and unhealthy lifestyle [2]. Systemic GCs, though not recommended by the ACR and recommended to be used at lowest dose in the European League Against Rheumatism (EULAR) treatment guidelines for PsA, are commonly used in clinical practice for acute flares of inflammatory arthritis $[9,10,105]$. The effects of GCs on glucose metabolism are well known, and they increase the risk of DM. Long-term use of low-dose steroids can cause hepatic insulin resistance, thus highlighting the importance of using steroids at the least possible doses for the shortest possible duration [106]. Methotrexate does not affect glucose metabolism and is considered safe in PsA patients with DM. Multiple studies looking at increases in hemoglobin A1c, fasting blood glucose or incident DM among methotrexate-treated PsA patients have found no effect on glucose metabolism [107-109]. It is important to note that NAFLD is common in DM, and methotrexate is associated with a significant increased risk of liver fibrosis in patients with DM compared to the group without DM, so close monitoring of LFTs is needed while on methotrexate [110]. There are no effects on glucose metabolism after treatment with leflunomide or sulfasalazine. Multiple studies have found a neutral impact of apremilast on glucose metabolism [111, 112].

A small study of 18 PsA patients evaluated the effect of TNFi and found no change in mean glucose level [113]. Another large study of 1200 PsA patients treated with adalimumab found no difference in the mean glucose levels between the adalimumab vs. placebo group [114]. These findings suggest that TNFi do not increase blood glucose levels and are safe in PsA patients with DM. IL-17 is being actively investigated as a cytokine of interest in the development of DM with evidence supporting a role of Th17 cells in the etiology of type $1 \mathrm{DM}$ and IL-17 playing a role in inflammation, insulin resistance and type 2 DM [115]. Egdeberg et al. studied the impact of ixekizumab for PsO on cardiovascular parameters and found no difference in fasting glucose at 60 weeks [116]. A pooled analysis of $>$ 3000 PsA patients treated with secukinumab showed a neutral effect of secukinumab on fasting plasma glucose level at 52 weeks [117] (Table 1). There are very limited data to date on the relationship between IL-12/23 inhibitors and glucose metabolism apart from a single retrospective study of 93 ustekinumab-treated PsA patients reporting an increase in fasting glucose level at 24 weeks [118]. Though there are no specific studies addressing DM and tofacitinib use in PsA, a large market scan database study over 11 years tried to address this in RA patients. The study of $>10,000$ patients with RA and DM found the risk of DM treatment intensification was lower in the tofacitinib cohort (HR 0.67, 95\% CI: 0.50, 0.90) compared with abatacept [119]. Much of the lower risk appeared to be driven by non-insulin DM treatment intensification events for tofacitinib [119].

\section{Neurologic Disorders}

Neurologic disorders are not commonly associated with PsA. The most common neurologic disorder reported in the Toronto Psoriatic Arthritis Clinic cohort was seizure disorder followed by neuropathy and multiple sclerosis (MS) [7]. The association among PsO, PsA and MS is controversial but must be considered in deciding the therapeutic agents [120, 121]. TNFi are associated with demyelinating diseases such as MS, Guillain-Barré syndrome and neuromyelitis optica and thus cannot be used in patients with these conditions [122]. Teriflunomide, which is the active metabolite of leflunomide, is approved for the treatment for 
MS and can be considered in patients with coexisting PsA [123]. Though there are reports of utility of methotrexate in MS, a Cochrane review found insufficient data to support the use of methotrexate in MS [124]. Blockade of IL$17 \mathrm{~A}$ has generated interest as a treatment option for MS, with secukinumab showing effectiveness In patients with relapsing-remitting MS, by reducing unique brain lesions and gadolinium-enhancing T1 lesions by $49 \%$ and $67 \%$, respectively [125]. Ustekinumab was not successful in reducing MS lesions and is not a feasible options for MS with PsA [126].

\section{EXTRA-ARTICULAR MANIFESTATIONS}

\section{Psoriasis}

PsA and PsO have a very high coexistence with PsA reported in 10-30\% of psoriasis patients [1]. In a study of 20,936 person-year follow-up, rate of new-onset PsA was 2.7 per 1000 person-years (CI 2.1-3.5) with corresponding 5-year incidence of $1.7 \%$ (CI 1.0-2.3\%) [127]. The major subtypes of psoriasis include plaque psoriasis, pustular psoriasis, guttate psoriasis, nail psoriasis, erythrodermic psoriasis and inverse psoriasis [128]. The most common type of psoriasis in a PsA cohort of 1593 patients was plaque psoriasis (79\%), and the most common site at initial presentation was scalp (42\%), followed by knees and elbows (35\%) [127]. Features of psoriasis that increase risk of PsA include number of cutaneous sites affected and location of psoriasis [129]. There was a 2.24-fold increased risk of PsA in those with more than 3 body sites affected, 3.98 increased risk with scalp lesions and 2.93 increased risk with nail dystrophy [127]. In the same study, PsA patients who presented at the same time with psoriasis were younger, male and more likely to have a family history of psoriasis [127]. Studies have also found an increased trend of obesity, trauma, bacterial infection, smoking, family history of PsA and physically demanding vocations to be associated with the development of PsA in patients with psoriasis [79].
The treatment of PsO includes topical therapies, such as topical corticosteroids, vitamin D analogs, tazarotene, calcineurin inhibitors, etc., which are not useful in PsA. Fortunately, there is a significant overlap between biologic and non-biologic therapies for PsO and PsA based on the guidelines from respective societies $[130,131]$. Methotrexate and apremilast are FDA approved for the treatment for $\mathrm{PsO}$ and can be used for PsA management [130, 131]. Tofacitinib has been shown to be efficacious for the treatment of PsO but is not yet FDA approved, though it is approved for the treatment of PsA $[131,132]$. Five TNF inhibitors have been approved for the treatment for PsA and four for the treatment for $\mathrm{PsO}$ (golimumab is not approved for PsO) $[131,133]$. In terms of IL-17 inhibitors, both secukinumab and ixekizumab are approved for treatment of PsO and PsA while brodalumab is only approved for treatment of PsO [133]. Ustekinumab and guselkumab have shown excellent efficacy results for treatment of PsO and PsA and are approved for treatment of both [133, 134]. Tildrakizumab and brodalumab are approved for PsO treatment but are not used in treating PsA.

There is significant overlap between therapies for PsA and concomitant PsO, and treatment decision should be based on the severity of symptoms (Table 1 ).

\section{Inflammatory Bowel Disease}

Gastrointestinal diseases such as Crohn's disease (CD) and ulcerative colitis (UC) are reportedly more common in PsA compared to $\mathrm{PsO}$ [135]. There are no specific guidelines differentiating treatment of PsA based on individual CD or UC diagnosis; however, the American College of Gastroenterology (ACG) has guidelines for each inflammatory bowel condition [136]. The ACG guidelines conditionally recommend avoiding NSAIDs in IBD. Certain csDMARDs such as sulfasalazine and methotrexate can be used in mild disease. Sulfasalazine can be used for treatment of mild-tomoderate colonic CD and UC. Methotrexate can also be used but typically given in doses up to $25 \mathrm{mg}$ once weekly intramuscularly or 
subcutaneously for those with steroid-dependent CD and for maintaining remission [136]. In UC, methotrexate is not recommended for induction or remission of moderate-severe disease.

Monoclonal TNFi (infliximab, adalimumab, certolizumab pegol) are used in moderate-severe CD and UC followed by IL-12/23 inhibition if there is failure of TNFi. Golimumab is approved for UC but not for CD and is effective in PsA. Vedolizumab, an integrin inhibitor, is approved for the treatment of CD and UC. It is not used for treatment of PsA but clinicians should be aware about the rare side effects of inflammatory arthritis and sacroiliitis reported with vedolizumab use [137]. Tofacitinib can also be used in those with moderate to severe UC [138]. Studies of tofacitinib use in CD have shown conflicting results [139]. Ustekinumab is typically reserved for patients who have failed TNFi therapy and csDMARD use. It can also be used in induction for moderate-severe CD with similar background therapy use or no prior exposure to TNFi as well as for maintenance of remission [136]. Similarly, ustekinumab was recently approved for inducing and maintaining remission for those with moderate-severe UC [140].

IL-17 inhibition works well for predominant cutaneous disease; however, there is caution in its use in patients with concomitant inflammatory bowel disease. Although rare, cases have been reported of patients who have had new onset or exacerbation of inflammatory bowel disease on IL-17 inhibition. In a 2-year span, 27 patients were identified in the literature to have IBD onset after IL-17 inhibition [141]. Causality however cannot be determined based on the nature of the review. Pooled cases from several studies involving 1380 PsA patients treated with secukinumab only revealed 7 new-onset cases of IBD [142]. In a safety follow-up study of ixekizumab users, incidence rate for IBD was $0.2 / 100$ patient-years [32]. The pooled exposure-adjusted incidence rate of CD across MEASURE-1 and MEASURE-2 studies in ankylosing spondylitis was 0.7 events per 100 patient-years of exposure to secukinumab; these cases were seen in patients with already pre-existing CD [30].
As there is such an extensive overlap between the therapeutic options for PsA and IBD, close collaboration between rheumatology, dermatology and gastroenterology is necessary to decide the optimal therapeutic agent (Table 1).

\section{Ophthalmic Diseases}

Uveitis is a well-recognized extra-articular manifestation associated with human leucocyte angigen-B27 (HLA-B27)-associated spondyloarthritis including PsA $[143,144]$. The risk of uveitis is significantly higher in PsA compared to patients with $\mathrm{PsO}$ and the general population [145]. A large systematic review of $>9500$ uveitis patients predicted the prevalence of uveitis in PsA as 25\% [144]. Although uveitis is frequently reported in PsA, other manifestations such as conjunctivitis, keratoconjunctivitis, etc., have been reported [146]. Multiple immunomodulators, such as methotrexate, mycophenolate, azathioprine and sulfasalazine, are used to treat non-infectious uveitis, though only a few are used in PsA $[147,148]$.

In recent years, biologic therapies have increased the treatment armamentarium for uveitis. While there are no specific data for uveitis in the PsA population, adalimumab and infliximab are effective in lowering the risk of uveitis flare or visual impairment [149, 150]. Etanercept is generally not effective in the treatment of uveitis while certolizumab and golimumab have shown lower risk of uveitis flares [151, 152]. In a pooled analysis of 3 clinical trials of 794 AS patients, there was no increased risk of uveitis with secukinumab use [153]. Ustekinumab has been reported to be successful in treatment of noninfectious uveitis associated with PsO, PsA and Crohn's disease $[154,155]$. As uveitis can be a vision-threatening manifestation of PsA, a collaborative approach among ophthalmology, rheumatology and dermatology is helpful in deciding a single agent that can control all manifestations of PsA (Table 1). 


\section{LINKED MANAGEMENT ISSUES}

\section{Chronic Infections}

All patients must be screened for hepatitis B virus (HBV), hepatitis $\mathrm{C}$ virus (HCV), human immunodeficiency virus (HIV) and latent tuberculosis (LTBI) prior to starting csDMARD or bDMARD therapy. Methotrexate increases the risk of $\mathrm{HBV}$ reactivation and can cause liver fibrosis/cirrhosis according to very limited reports [156]. As methotrexate is widely used and there are only a few cases related to HBV reactivation, the risk of HBV reactivation is $<1 \%$ [157]. There is a known risk of opportunistic infections and reactivation of HIV and LTBI patients, respectively $[158,159]$. TNF- $\alpha$ is crucial for clearance and containment of infections such as HBV and LTBI [160]. Inhibition of TNF- $\alpha$ can lead to HBV re-activation, and a metaanalysis of pooled dermatologic and rheumatic patients suggested that recurrence of HBV ranged from 4.2 to $6.8 \%$, with higher HBV recurrences in HbsAg-positive patients [161]. HbsAgpositive patients are at higher re-activation of HBV compared to anti-HBc-positive patients. Patients on TNFi with positive anti-Hbc antibody are at moderate risk of HBV re-activation, and treatment with anti-viral drugs or routine monitoring must be decided based on risk profile [157]. Etanercept appears safe, at least with short-term use, in the management of PsA patients with concomitant HCV [162]. Chiu et al. reported HCV and HBV re-activation in ustekinumab-treated patients while Abuchar et al. reported no reactivation of $\mathrm{HCV}$ $[163,164]$. The data regarding safety of IL-12/23 inhibitors with HBV are limited but preliminary reports suggest they are safe to use $[165,166]$. TNF- $\alpha$ is crucial for granuloma formation, and inhibition of TNF- $\alpha$ can lead to reactivation of LTBI [167]. The risk of LTBI is present with all TNFi but is highest with infliximab. It is recommended that patients be treated with LTB prophylaxis for 4-6 weeks prior to commencing TNFi therapy. The IL-17 inhibitors and IL12/23 inhibitors have not been shown to substantially increase the risk of LTBI re-activation [168-170].

\section{Psychiatric Illness}

Mental health disorders such as depression and anxiety have a reported prevalence of $9-37 \%$ in PsA, which is higher than the general population [171, 172]. The relationship between depression and systemic inflammation is still unclear but is an important co-morbidities to consider as it can affect pain and the likelihood of disease remission [173]. Another challenge in patients with depression and PsA is treatment adherence, which can impact disease activity and quality of life [174]. Assessment of psychiatric co-morbidities is important as some treatment options such as brodalumab and apremilast come with FDA label warning of increased risk of mental health outcome such as self-harm [175, 176]. Similarly, studies have tried to evaluate the effect of csDMARD/ bDMARD therapy and relevant mental health with favorable outcomes. A Swedish registrybased study looked at the use of anti-depressants in patients with PsA, RA and AS and found that the use of anti-depressants was reduced after starting treatment with DMARDs or TNFi [177]. Biologic medications have shown some encouraging results in the treatment of depression in patients with PsO without PsA [178]. A large cohort study of PsA or PsO patients from Taiwan examined the effects of biologic therapy on reducing depression and noted a 40\% decrease in the prevalence after 2 years of biologic therapy [179]. An integrated pooled clinical trial safety dataset from 21 randomized controlled clinical trials of secukinumab in PsO, PsA and AS reported low incidence of suiciderelated events in the treatment group [180].

Physicians must pay attention to psychiatric co-morbidities in PsA as it not only determines the treatment choice but can very well affect treatment adherence and clinical outcomes (Table 1).

\section{Pregnancy}

The burden of rheumatic disease is high among women, especially those of child-bearing age. The choice of therapy and disease activity can weigh heavily on conception and during 
gestation. A retrospective analysis by Karmacharya et al. showed a 3\% increase in incidence of females with PsA from 2000 to 2017, primarily in age groups 40-59 years [181]. The goal of therapy for successful gestation is to control activity prior to and during pregnancy. A systemic literature search of pregnant patients with PsA revealed elevated disease activity port partum and increased risk of preterm birth, preeclampsia and elective cesarean section among patients [182]. Four out of five studies regarding pregnancy in PsA found no adverse pregnancy outcomes [183]. Another study showed a risk of preterm delivery correlating to PsA disease activity [184].

PsA medications typically safe to use in pregnancy include NSAIDs prior to third trimester, prednisone $<20 \mathrm{mg} /$ daily, sulfasalazine and TNFi [185] (Table 1). Medications including steroids, non-bDMARDs, bDMARDs and NSAIDs in the first or second trimester were not associated with increased risk of preterm delivery [184]. There are limited data regarding use of IL-17 inhibition, IL12/23 inhibition, IL-23 inhibition, PDE-4 inhibition and JAK/STAT inhibition; therefore, consensus is to modify therapy prior to planned pregnancy $[185,186]$. Methotrexate and leflunomide are contraindicated $[185,186]$. In one retrospective case series, discontinuation of biologics prior to pregnancy was found to be associated with a flare in disease activity during pregnancy with increased use of steroids; there was no significant change in disease activity in those continued on biologics [187].

\section{Fertility}

The relationship between PsA and infertility is unclear [188]. In a study of 74 PsA patients, the diagnosis of infertility was not significantly different compared to 74 healthy controls [188]. Infertility, defined as being unable to get pregnant after 12 months of trying or physician diagnosis of infertility, was assessed based on a questionnaire in 28 PsA patients, and 10 patients (36\%) who had ever been pregnant or attempted pregnancy reported infertility with polycyclic ovarian syndrome being the predominant cause $(5 / 10)$ [189].

Certain medications are thought to influence fertility and pregnancy outcomes. Although teratogenic, the risk of infertility with methotrexate use appears low with one report stating successful conception in women after methotrexate cessation [190]. There are no clear associations between methotrexate use and male fertility [191]. Although not many human models, animal studies show that leflunomide, in its active form, does not influence fertility however is embryotoxic and teratogenic [192]. If there is difficulty with conception and significant NSAID use, NSAIDs are recommended to be discontinued pre-conception because of the risk of un-ruptured follicle syndrome $[185,192]$. Sulfasalazine has been found to reduce male fertility in a setting of reversible azoospermia but is safe in females [192, 193]. There are no clear recommendations for use of JAKi and tsDMARDs due to lack of data [185]. No data are available regarding use of anti-IL-17 and anti-IL-12/23 in female fertility.

\section{CONCLUSION}

PsA is a complex disease, and there has been tremendous progress in our understanding about the associated co-morbidities. Individual co-morbid conditions in PsA present a unique challenge in deciding the treatment choice and attaining successful treatment. The goal of therapy is to control the immune-mediated inflammation directed by active PsA and extraarticular manifestations. Certain co-morbidities help dictate treatment choices and can affect the response to treatment. The burden of $\mathrm{CV}$ disease is high in PsA, and treatment of underlying inflammatory arthritis has been shown to improve CV outcomes. Obesity is a risk factor for PsA development and has been shown to adversely affect response to treatment. The risk of malignancy is low with the available bDMARD therapies, but patients should be made aware about the risk. As PsA is a heterogeneous disease that can have ocular, cutaneous or gastrointestinal manifestations, close collaboration between specialties is crucial in deciding 
the optimal drug therapy. Screening for chronic infections and renal and hepatic dysfunction is recommended prior to therapy initiation. A shared decision model must be utilized concerning the appropriate drug choice based on the disease presentation, associated co-morbidities and individual needs of a patient.

\section{ACKNOWLEDGEMENTS}

Funding. No funding or sponsorship was received for this study or publication of this article. The Rapid Service Fee was funded by the authors.

Authorship. All named authors meet the International Committee of Medical Journal Editors (ICMJE) criteria for authorship for this article, take responsibility for the integrity of the work as a whole, and have given their approval for this version to be published.

Authorship Contributions. Both authors (Sneha Patel and Anand Kumthekar) contributed equally to the study.

Disclosures. Sneha Patel and Anand Kumthekar have nothing to disclose.

Compliance with Ethics Guidelines. The work has been compliant with ethics guidelines and this article does not contain any studies involving human participants performed by any of the authors.

Open Access. This article is licensed under a Creative Commons Attribution-NonCommercial 4.0 International License, which permits any non-commercial use, sharing, adaptation, distribution and reproduction in any medium or format, as long as you give appropriate credit to the original author(s) and the source, provide a link to the Creative Commons licence, and indicate if changes were made. The images or other third party material in this article are included in the article's Creative Commons licence, unless indicated otherwise in a credit line to the material. If material is not included in the article's Creative Commons licence and your intended use is not permitted by statutory regulation or exceeds the permitted use, you will need to obtain permission directly from the copyright holder. To view a copy of this licence, visit http://creativecommons.org/licenses/bync/4.0/.

\section{REFERENCES}

1. Alinaghi F, Calov M, Kristensen LE, Gladman DD, Coates LC, Jullien D, et al. Prevalence of psoriatic arthritis in patients with psoriasis: a systematic review and meta-analysis of observational and clinical studies. J Am Acad Dermatol. 2019;80(1): 251-65e19.

2. Husni ME. Comorbidities in psoriatic arthritis. Rheum Dis Clin. 2015;41(4):677-98.

3. Husted JA, Thavaneswaran A, Chandran V, Eder L, Rosen CF, Cook RJ, et al. Cardiovascular and other comorbidities in patients with psoriatic arthritis: a comparison with patients with psoriasis. Arthritis Care Res. 2011;63(12):1729-35.

4. Ogdie A, Schwartzman S, Eder L, Maharaj AB, Zisman D, Raychaudhuri SP, et al. Comprehensive treatment of psoriatic arthritis: managing comorbidities and extraarticular manifestations. J Rheumatol. 2014;41(11):2315-22.

5. Zhao SS, Miller N, Harrison N, Duffield SJ, Dey M, Goodson NJ. Systematic review of mental health comorbidities in psoriatic arthritis. Clin Rheumatol. 2020;39(1):217-25.

6. Salaffi F, Carotti M, Gasparini S, Intorcia M, Grassi $\mathrm{W}$. The health-related quality of life in rheumatoid arthritis, ankylosing spondylitis, and psoriatic arthritis: a comparison with a selected sample of healthy people. Health Qual Life Outcomes. 2009;7: 25.

7. Husted JA, Thavaneswaran A, Chandran V, Eder L, Rosen CF, Cook RJ, et al. Cardiovascular and other comorbidities in patients with psoriatic arthritis: a comparison with patients with psoriasis. Arthritis Care Res (Hoboken). 2011;63(12):1729-35.

8. Ogdie A, Coates LC, Gladman DD. Treatment guidelines in psoriatic arthritis. Rheumatology (Oxford). 2020;59(Suppl 1):i37-46.

9. Singh JA, Guyatt G, Ogdie A, Gladman DD, Deal C, Deodhar A, et al. 2018 American College of Rheumatology/National Psoriasis Foundation 
guideline for the treatment of psoriatic arthritis. Arthritis Care Res. 2019;71(1):2-29.

10. Gossec L, Baraliakos X, Kerschbaumer A, de Wit M, McInnes I, Dougados $\mathrm{M}$, et al. EULAR recommendations for the management of psoriatic arthritis with pharmacological therapies: 2019 update. Ann Rheum Dis. 2020;79(6):700.

11. Ogdie A, Yu Y, Haynes K, Love TJ, Maliha S, Jiang Y, et al. Risk of major cardiovascular events in patients with psoriatic arthritis, psoriasis and rheumatoid arthritis: a population-based cohort study. Ann Rheum Dis. 2015;74(2):326-32.

12. Eder L, Dey A, Joshi AA, Boehncke W-H, Mehta NN, Szentpetery A. Cardiovascular diseases in psoriasis and psoriatic arthritis. J Rheumatol Suppl. 2019;95: 20-7.

13. Charles-Schoeman C, DeMasi R, Valdez H, Soma K, Hwang LJ, Boy MG, et al. Risk factors for major adverse cardiovascular events in phase iii and longterm extension studies of tofacitinib in patients with rheumatoid arthritis. Arthritis Rheumatol (Hoboken, NJ). 2019;71(9):1450-9.

14. Singh JA, Guyatt G, Ogdie A, Gladman DD, Deal C, Deodhar A, et al. 2018 American College of Rheumatology/National Psoriasis Foundation guideline for the treatment of psoriatic arthritis. Arthritis Rheumatol. 2019;71(1):5-32.

15. Schmidt M, Lamberts M, Olsen A-MS, Fosbøll E, Niessner A, Tamargo J, et al. Cardiovascular safety of non-aspirin non-steroidal anti-inflammatory drugs: review and position paper by the working group for Cardiovascular Pharmacotherapy of the European Society of Cardiology. Eur Heart J. 2016;37(13): 1015-23.

16. Farran Ortega L, Tormo Ratera M, Lluch Pons J, Mora M, Marco Pascual C, González Giménez X, et al. AB0764 safety of systemic corticosteroids in a short regimen in patients with psoriatic arthritis. Retrospective analysis of a large observational cohort. Ann Rheum Dis. 2020;79(Suppl 1):1680.

17. Li L, Hagberg KW, Peng M, Shah K, Paris M, Jick S. Rates of cardiovascular disease and major adverse cardiovascular events in patients with psoriatic arthritis compared to patients without psoriatic arthritis. J Clin Rheumatol. 2015;21(8):405.

18. Roubille C, Richer V, Starnino T, McCourt C, McFarlane A, Fleming P, et al. The effects of tumour necrosis factor inhibitors, methotrexate, non-steroidal anti-inflammatory drugs and corticosteroids on cardiovascular events in rheumatoid arthritis, psoriasis and psoriatic arthritis: a systematic review and meta-analysis. Ann Rheum Dis. 2015;74(3): 480-9.
19. Deyab G, Hokstad I, Whist JE, Smastuen MC, Agewall S, Lyberg T, et al. Methotrexate and anti-tumor necrosis factor treatment improves endothelial function in patients with inflammatory arthritis. Arthritis Res Ther. 2017;19(1):232.

20. Ridker PM, Everett BM, Pradhan A, MacFadyen JG, Solomon DH, Zaharris E, et al. Low-dose methotrexate for the prevention of atherosclerotic events. N Engl J Med. 2018;380(8):752-62.

21. Ahlehoff O, Skov L, Gislason G, Gniadecki R, Iversen L, Bryld LE, et al. Cardiovascular outcomes and systemic anti-inflammatory drugs in patients with severe psoriasis: 5-year follow-up of a Danish nationwide cohort. J Eur Acad Dermatol Venereol. 2015;29(6):1128-34.

22. Armstrong EJ, Harskamp CT, Armstrong AW. Psoriasis and major adverse cardiovascular events: a systematic review and meta-analysis of observational studies. J Am Heart Assoc. 2013;2(2):e000062.

23. Gulliver WP, Young HM, Bachelez H, Randell S, Gulliver S, Al-Mutairi N. Psoriasis patients treated with biologics and methotrexate have a reduced rate of myocardial infarction: a collaborative analysis using international cohorts. J Cutan Med Surg. 2016;20(6):550-4.

24. Yuan S, Carter P, Bruzelius M, Vithayathil M, Kar S, Mason AM, et al. Effects of tumour necrosis factor on cardiovascular disease and cancer: A two-sample Mendelian randomization study. EBioMedicine. 2020;54.

25. Persson R, Hagberg KW, Qian Y, Vasilakis-Scaramozza C, Jick S. The risks of major cardiac events among patients with psoriatic arthritis treated with apremilast, biologics, DMARDs or corticosteroids. Rheumatology (Oxford). 2021;60(4):1926-31.

26. Yang ZS, Lin NN, Li L, Li Y. The effect of TNF inhibitors on cardiovascular events in psoriasis and psoriatic arthritis: an updated meta-analysis. Clin Rev Allergy Immunol. 2016;51(2):240-7.

27. Chung ES, Packer M, Lo KH, Fasanmade AA, Willerson JT. Randomized, double-blind, placebocontrolled, pilot trial of infliximab, a chimeric monoclonal antibody to tumor necrosis factor-alpha, in patients with moderate-to-severe heart failure: results of the anti-TNF Therapy Against Congestive Heart Failure (ATTACH) trial. Circulation. 2003;107(25):3133-40.

28. Bozkurt B, Torre-Amione G, Warren MS, Whitmore J, Soran OZ, Feldman AM, et al. Results of targeted anti-tumor necrosis factor therapy with etanercept (ENBREL) in patients with advanced heart failure. Circulation. 2001;103(8):1044-7. 
29. von Stebut E, Reich K, Thaçi D, Koenig W, Pinter A, Körber A, et al. Impact of secukinumab on endothelial dysfunction and other cardiovascular disease parameters in psoriasis patients over 52 weeks. J Invest Dermatol. 2019;139(5):1054-62.

30. Baeten D, Sieper J, Braun J, Baraliakos X, Dougados M, Emery P, et al. Secukinumab, an interleukin-17A inhibitor, in ankylosing spondylitis. N Engl J Med. $2015 ; 373(26): 2534-48$.

31. Mease PJ, McInnes IB, Kirkham B, Kavanaugh A, Rahman P, van der Heijde D, et al. Secukinumab inhibition of interleukin-17A in patients with psoriatic arthritis. N Engl J Med. 2015;373(14):1329-39.

32. Armstrong A, Paul C, Puig L, Boehncke WH, Freeman M, Torii $\mathrm{H}$, et al. Safety of ixekizumab treatment for up to 5 years in adult patients with moderate-to-severe psoriasis: results from greater than 17,000 patient-years of exposure. Dermatol Ther (Heidelb). 2020;10(1):133-50.

33. Lee MP, Desai RJ, Jin Y, Brill G, Ogdie A, Kim SC. Association of ustekinumab vs TNF inhibitor therapy with risk of atrial fibrillation and cardiovascular events in patients with psoriasis or psoriatic arthritis. JAMA Dermatol. 2019;155(6):700-7.

34. Champs B, Degboé Y, Barnetche T, Cantagrel A, Ruyssen-Witrand A, Constantin A. Short-term risk of major adverse cardiovascular events or congestive heart failure in patients with psoriatic arthritis or psoriasis initiating a biological therapy: a metaanalysis of randomised controlled trials. RMD Open. 2019;5(1):e000763.

35. Administration USFaD. FDA requires warnings about increased risk of serious heart-related events, cancer, blood clots, and death for JAK inhibitors that treat certain chronic inflammatory conditions 2021 [9/1/21]. https://www.fda.gov/drugs/drugsafety-and-availability/fda-requires-warningsabout-increased-risk-serious-heart-related-eventscancer-blood-clots-and-death. Accessed 2 Sept 2021.

36. Gladman DD, Charles-Schoeman C, McInnes IB, Veale DJ, Thiers B, Nurmohamed M, et al. Changes in lipid levels and incidence of cardiovascular events following tofacitinib treatment in patients with psoriatic arthritis: a pooled analysis across phase iii and long-term extension studies. Arthritis Care Res. 2019;71(10):1387-95.

37. Mease PJ, Lertratanakul A, Anderson JK, Papp K, Van den Bosch F, Tsuji S, et al. Upadacitinib for psoriatic arthritis refractory to biologics: SELECTPsA 2. Ann Rheum Dis. 2021;80(3):312-20.

38. Vaengebjerg S, Skov L, Egeberg A, Loft ND. Prevalence, incidence, and risk of cancer in patients with psoriasis and psoriatic arthritis: a systematic review and meta-analysis. JAMA Dermatol. 2020;156(4): 421-9.

39. Trafford AM, Parisi R, Kontopantelis E, Griffiths CEM, Ashcroft DM. Association of psoriasis with the risk of developing or dying of cancer: a systematic review and meta-analysis. JAMA Dermatol. 2019;155(12):1390-403.

40. Rohekar S, Tom BDM, Hassa A, Schentag CT, Farewell VT, Gladman DD. Prevalence of malignancy in psoriatic arthritis. Arthritis Rheum. 2008;58(1): 82-7.

41. Wilton KM, Crowson CS, Matteson EL. Malignancy incidence in patients with psoriatic arthritis: a comparison cohort-based incidence study. Clin Rheumatol. 2016;35(10):2603-7.

42. Nyfors A, Jensen H. Frequency of malignant neoplasms in 248 long-term methotrexate-treated psoriatics. A preliminary study. Dermatologica. 1983;167(5):260-1.

43. Fiorentino D, Ho V, Lebwohl MG, Leite L, Hopkins $\mathrm{L}$, Galindo C, et al. Risk of malignancy with systemic psoriasis treatment in the Psoriasis Longitudinal Assessment Registry. J Am Acad Dermatol. 2017;77(5):845-54.

44. Wang J-L, Yin W-J, Zhou L-Y, Zhou G, Liu K, Hu C, et al. Risk of non-melanoma skin cancer for rheumatoid arthritis patients receiving TNF antagonist: a systematic review and meta-analysis. Clin Rheumatol. 2020;39(3):769-78.

45. Dommasch ED, Abuabara K, Shin DB, Nguyen J, Troxel AB, Gelfand JM. The risk of infection and malignancy with tumor necrosis factor antagonists in adults with psoriatic disease: a systematic review and meta-analysis of randomized controlled trials. J Am Acad Dermatol. 2011;64(6):1035-50.

46. Bonovas S, Minozzi S, Lytras T, González-Lorenzo M, Pecoraro V, Colombo S, et al. Risk of malignancies using anti-TNF agents in rheumatoid arthritis, psoriatic arthritis, and ankylosing spondylitis: a systematic review and meta-analysis. Expert Opin Drug Saf. 2016;15(sup1):35-54.

47. Costa L, Caso F, Del Puente A, Di Minno MN, Peluso $\mathrm{R}$, Scarpa R. Incidence of malignancies in a cohort of psoriatic arthritis patients taking traditional disease modifying antirheumatic drug and tumor necrosis factor inhibitor therapy: an observational study. J Rheumatol. 2016;43(12):2149-54.

48. Hellgren K, Dreyer L, Arkema EV, Glintborg B, Jacobsson LTH, Kristensen L-E, et al. Cancer risk in patients with spondyloarthritis treated with TNF inhibitors: a collaborative study from the ARTIS and 
DANBIO registers. Ann Rheum Dis. 2017;76(1): 105-11.

49. Dreyer L, Cordtz RL, Hansen IMJ, Kristensen LE, Hetland ML, Mellemkjaer L. Risk of second malignant neoplasm and mortality in patients with rheumatoid arthritis treated with biological DMARDs: a Danish population-based cohort study. Ann Rheum Dis. 2018;77(4):510-4.

50. Maneiro JR, Souto A, Gomez-Reino JJ. Risks of malignancies related to tofacitinib and biological drugs in rheumatoid arthritis: systematic review, meta-analysis, and network meta-analysis. Semin Arthritis Rheum. 2017;47(2):149-56.

51. Xie W, Yang X, Huang H, Gao D, Ji L, Zhang Z. Risk of malignancy with non-TNFi biologic or tofacitinib therapy in rheumatoid arthritis: a meta-analysis of observational studies. Semin Arthritis Rheum. 2020;50(5):930-7.

52. Cohen SB, van Vollenhoven RF, Winthrop KL, Zerbini CAF, Tanaka Y, Bessette L, et al. Safety profile of upadacitinib in rheumatoid arthritis: integrated analysis from the SELECT phase III clinical programme. Ann Rheum Dis. 2021;80(3):304.

53. Papp KA, Griffiths CEM, Gordon K, Lebwohl M, Szapary PO, Wasfi Y, et al. Long-term safety of ustekinumab in patients with moderate-to-severe psoriasis: final results from 5 years of follow-up. Br J Dermatol. 2013;168(4):844-54.

54. Lebwohl M, Deodhar A, Griffiths CEM, Menter MA, Poddubnyy $\mathrm{D}$, Bao $\mathrm{W}$, et al. The risk of malignancy in patients with secukinumab-treated psoriasis, psoriatic arthritis and ankylosing spondylitis: analysis of clinical trial and postmarketing surveillance data with up to five years of follow-up. Br J Dermatol. 2021.

55. Genovese MC, Mysler E, Tomita T, Papp KA, Salvarani C, Schwartzman S, et al. Safety of ixekizumab in adult patients with plaque psoriasis, psoriatic arthritis and axial spondyloarthritis: data from 21 clinical trials. Rheumatology. 2020;59(12):3834-44.

56. Pakchotanon R, Ye Y, Cook RJ, Chandran V, Gladman DD. Liver abnormalities in patients with psoriatic arthritis. J Rheumatol. 2019; p. jrheum. 181312.

57. Ogdie A, Grewal SK, Noe MH, Shin DB, Takeshita J, Chiesa Fuxench ZC, et al. Risk of incident liver disease in patients with psoriasis, psoriatic arthritis, and rheumatoid arthritis: a Population-Based Study. J Invest Dermatol. 2018;138(4):760-7.

58. Lee E, Han JH, Bang CH, Yoo SA, Han KD, Kim H-N, et al. Risk of End-stage renal disease in psoriatic patients: real-world data from a Nationwide
Population-Based Cohort Study. Sci Rep. 2019;9(1): 16581.

59. Mori S, Arima N, Ito M, Ueki Y, Abe Y, Aoyagi K, et al. Incidence, predictive factors and severity of methotrexate-related liver injury in rheumatoid arthritis: a longitudinal cohort study. Rheumatol Adv Pract. 2020;4(2).

60. Malatjalian DA, Ross JB, Williams CN, Colwell SJ, Eastwood BJ. Methotrexate hepatotoxicity in psoriatics: report of 104 patients from Nova Scotia, with analysis of risks from obesity, diabetes and alcohol consumption during long term follow-up. Can J Gastroenterol. 1996;10(6):369-75.

61. LiverTox: Clinical and Research Information on Drug-Induced Liver Injury [Internet] [Internet]. 2012. https://www.ncbi.nlm.nih.gov/books/ NBK547852/. Accessed 2 Sept 2021.

62. Gelfand JM, Wan J, Zhang H, Shin DB, Ogdie A, Syed MN, et al. Risk of liver disease in patients with psoriasis, psoriatic arthritis, and rheumatoid arthritis receiving methotrexate: a populationbased study. J Am Acad Dermatol. 2021;84(6): 1636-43.

63. Lee S-W, Park H-J, Kim BK, Han K-H, Lee S-K, Kim $\mathrm{SU}$, et al. Leflunomide increases the risk of silent liver fibrosis in patients with rheumatoid arthritis receiving methotrexate. Arthritis Res Ther. 2012;14(5):R232.

64. Tang K-T, Dufour J-F, Chen P-H, Hernaez R, Hutfless $S$. Antitumour necrosis factor- $\alpha$ agents and development of new-onset cirrhosis or non-alcoholic fatty liver disease: a retrospective cohort. BMJ Open Gastroenterol. 2020;7(1):e000349.

65. Ghabril M, Bonkovsky HL, Kum C, Davern T, Hayashi $\mathrm{PH}$, Kleiner DE, et al. Liver injury from tumor necrosis factor- $\alpha$ antagonists: analysis of thirty-four cases. Clin Gastroenterol Hepatol. 2013;11(5):558-64.e3.

66. Soriano ER, Madariaga H, Castañeda O, Citera G, Schneeberger EE, Cardiel MH, et al. FRI0099 Liver enzyme abnormalities after tofacitinib treatment in patients with hepatic steatosis from the rheumatoid arthritis, psoriatic arthritis and psoriasis clinical programmes. Ann Rheum Dis. 2018;77(Suppl 2): 593.

67. McInnes IB, Anderson JK, Magrey M, Merola JF, Liu $\mathrm{Y}$, Kishimoto $\mathrm{M}$, et al. Trial of upadacitinib and adalimumab for psoriatic arthritis. N Engl J Med. 2021;384(13):1227-39.

68. Prussick RB, Miele L. Nonalcoholic fatty liver disease in patients with psoriasis: a consequence of 
systemic inflammatory burden? Br J Dermatol. 2018;179(1):16-29.

69. Lucas GNC, Leitão ACC, Alencar RL, Xavier RMF, Daher EDF, Silva Junior GBD. Pathophysiological aspects of nephropathy caused by non-steroidal anti-inflammatory drugs. J Brasil Nefrolog. 2019;41(1):124-30.

70. Erdbrügger U, de Groot K. Is methotrexate nephrotoxic? Dose-dependency, comorbidities and comedication. Z Rheumatol. 2011;70(7):549-52.

71. Hayashi K, Sada K-E, Asano Y, Asano SH, Yamamura $\mathrm{Y}$, Ohashi K, et al. Risk of higher dose methotrexate for renal impairment in patients with rheumatoid arthritis. Sci Rep. 2020;10(1):18715.

72. Kremer JM, Petrillo GF, Hamilton RA. Pharmacokinetics and renal function in patients with rheumatoid arthritis receiving a standard dose of oral weekly methotrexate: association with significant decreases in creatinine clearance and renal clearance of the drug after 6 months of therapy. J Rheumatol. 1995;22(1):38-40.

73. Schiff $M H$, Whelton A. Renal toxicity associated with disease-modifying antirheumatic drugs used for the treatment of rheumatoid arthritis. Semin Arthritis Rheum. 2000;30(3):196-208.

74. Hueber AJ, Tunc A, Schett G, Manger B. Anti-tumour necrosis factor alpha therapy in patients with impaired renal function. Ann Rheum Dis. 2007;66(7):981-2.

75. Toussirot E, Streit G, Wendling D. The contribution of adipose tissue and adipokines to inflammation in joint diseases. Curr Med Chem. 2007;14(10): 1095-100.

76. Kumthekar A, Ogdie A. Obesity and psoriatic arthritis: a narrative review. Rheumatol Therapy. 2020;7:447-56.

77. Soltani-Arabshahi R, Wong B, Feng BJ, Goldgar DE, Duffin KC, Krueger GG. Obesity in early adulthood as a risk factor for psoriatic arthritis. Arch Dermatol. 2010;146(7):721-6.

78. Li W, Han J, Qureshi AA. Obesity and risk of incident psoriatic arthritis in US women. Ann Rheum Dis. 2012;71(8):1267-72.

79. Eder L, Haddad A, Rosen CF, Lee KA, Chandran V, Cook R, et al. The incidence and risk factors for psoriatic arthritis in patients with psoriasis: a prospective cohort study. Arthritis Rheumatol. 2016;68(4):915-23.

80. Walsh JA, Wan MT, Willinger C, Husni ME, Scher $\mathrm{JU}$, Reddy SM, et al. Measuring outcomes in psoriatic arthritis: comparing Routine Assessment of Patient Index Data (RAPID3) and Psoriatic Arthritis Impact of Disease (PSAID). J Rheumatol. 2019.

81. Polyzos SA, Kountouras J, Mantzoros CS. Obesity and nonalcoholic fatty liver disease: from pathophysiology to therapeutics. Metabolism. 2019;92: 82-97.

82. Gisondi P, Barba E, Girolomoni G. Non-alcoholic fatty liver disease fibrosis score in patients with psoriasis. J Eur Acad Dermatol Venereol. 2016;30(2): 282-7.

83. Ogdie A, Grewal SK, Noe MH, Shin DB, Takeshita J, Fuxench ZCC, et al. Risk of incident liver disease in patients with psoriasis, psoriatic arthritis, and rheumatoid arthritis: a population-based study. J Investig Dermatol. 2018;138(4):760-7.

84. Lindsay K, Fraser AD, Layton A, Goodfield M, Gruss $\mathrm{H}$, Gough A. Liver fibrosis in patients with psoriasis and psoriatic arthritis on long-term, high cumulative dose methotrexate therapy. Rheumatology. 2009;48(5):569-72.

85. Menter A, Korman NJ, Elmets CA, Feldman SR, Gelfand JM, Gordon KB, et al. Guidelines of care for the management of psoriasis and psoriatic arthritis: section 4 . Guidelines of care for the management and treatment of psoriasis with traditional systemic agents. J Am Acad Dermatol. 2009;61(3):451-85.

86. Singh JA, Saag KG, Bridges SL Jr, Akl EA, Bannuru RR, Sullivan MC, et al. 2015 American College of Rheumatology Guideline for the Treatment of Rheumatoid Arthritis. Arthritis Care Res (Hoboken). 2016;68(1):1-25.

87. Cutolo M, Myerson GE, Fleischmann RM, Lioté F, Díaz-González F, Van den Bosch F, et al. A phase III, randomized, controlled trial of apremilast in patients with psoriatic arthritis: results of the PALACE 2 trial. J Rheumatol. 2016;43(9):1724-34.

88. Mantravadi S, Ogdie A, Kraft WK. Tumor necrosis factor inhibitors in psoriatic arthritis. Expert Rev Clin Pharmacol. 2017;10(8):899-910.

89. Caso F, Del Puente A, Oliviero F, Peluso R, Girolimetto N, Bottiglieri P, et al. Metabolic syndrome in psoriatic arthritis: the interplay with cutaneous involvement. Evidences from literature and a recent cross-sectional study. Clin Rheumatol. 2018;37(3): 579-86.

90. Marcora SM, Chester KR, Mittal G, Lemmey AB, Maddison PJ. Randomized phase 2 trial of anti-tumor necrosis factor therapy for cachexia in patients with early rheumatoid arthritis. Am J Clin Nutr. 2006;84(6):1463-72. 
91. Renzo LDI, Saraceno R, Schipani C, Rizzo M, Bianchi A, Noce A, et al. Prospective assessment of body weight and body composition changes in patients with psoriasis receiving anti-TNF- $\alpha$ treatment. Dermatol Ther. 2011;24(4):446-51.

92. Tan E, Baker C, Foley P. Weight gain and tumour necrosis factor-alpha inhibitors in patients with psoriasis. Australas J Dermatol. 2013;54(4):259-63.

93. Singh S, Facciorusso A, Singh AG, Vande Casteele N, Zarrinpar A, Prokop LJ, et al. Obesity and response to anti-tumor necrosis factor-alpha agents in patients with select immune-mediated inflammatory diseases: a systematic review and meta-analysis. PLoS ONE. 2018;13(5):e0195123.

94. di Minno MN, Peluso R, Iervolino S, Lupoli R, Russolillo A, Scarpa R, et al. Obesity and the prediction of minimal disease activity: a prospective study in psoriatic arthritis. Arthritis Care Res (Hoboken). 2013;65(1):141-7.

95. Hojgaard P, Glintborg B, Kristensen LE, Gudbjornsson B, Love TJ, Dreyer L. The influence of obesity on response to tumour necrosis factor-alpha inhibitors in psoriatic arthritis: results from the DANBIO and ICEBIO registries. Rheumatology (Oxford). 2016;55(12):2191-9.

96. Ogdie A, Palmer JL, Greenberg J, Curtis JR, Harrold LR, Solomon DH, et al. Predictors of achieving remission among patients with psoriatic arthritis initiating a tumor necrosis factor inhibitor. J Rheumatol. 2019;46(5):475-82.

97. Klingberg E, Bilberg A, Bjorkman S, Hedberg M, Jacobsson L, Forsblad-d'Elia H, et al. Weight loss improves disease activity in patients with psoriatic arthritis and obesity: an interventional study. Arthritis Res Ther. 2019;21(1):17.

98. Di Minno MN, Peluso R, Iervolino S, Russolillo A, Lupoli R, Scarpa R, et al. Weight loss and achievement of minimal disease activity in patients with psoriatic arthritis starting treatment with tumour necrosis factor alpha blockers. Ann Rheum Dis. 2014;73(6):1157-62.

99. Gisondi P, Conti A, Galdo G, Piaserico S, De Simone C, Girolomoni G. Ustekinumab does not increase body mass index in patients with chronic plaque psoriasis: a prospective cohort study. Br J Dermatol. 2013;168(5):1124-7.

100. Reich K, Puig L, Mallbris L, Zhang L, Osuntokun O, Leonardi C. The effect of bodyweight on the efficacy and safety of ixekizumab: results from an integrated database of three randomised, controlled Phase 3 studies of patients with moderate-to-severe plaque psoriasis. J Eur Acad Dermatol Venereol. 2017;31(7): 1196-207.
101. Pantano I, Iacono D, Favalli EG, Scalise G, Costa L, Caso F, et al. Secukinumab efficacy in patients with PsA is not dependent on patients' body mass index. Ann Rheum Dis. 2020.

102. Giles JT, Ogdie A, Reino JJG, Helliwell P, Germino R, Stockert L, et al. Impact of baseline body mass index on the efficacy and safety of tofacitinib in patients with psoriatic arthritis. RMD Open. 2021;7:1-11.

103. Dubreuil M, Rho YH, Man A, Zhu Y, Zhang Y, Love $\mathrm{TJ}$, et al. Diabetes incidence in psoriatic arthritis, psoriasis and rheumatoid arthritis: a UK populationbased cohort study. Rheumatology. 2014;53(2): 346-52.

104. Eder L, Chandran V, Cook R, Gladman DD. The risk of developing diabetes mellitus in patients with psoriatic arthritis: a cohort study. J Rheumatol. 2017;44(3):286-91.

105. Aimo C, Cosentino VL, Sequeira G, Kerzberg E. Use of systemic glucocorticoids in patients with psoriatic arthritis by Argentinian and other Latin-American rheumatologists. Rheumatol Int. 2019;39(4): 723-7.

106. Petersons CJ, Mangelsdorf BL, Jenkins AB, Poljak A, Smith MD, Greenfield JR, et al. Effects of low-dose prednisolone on hepatic and peripheral insulin sensitivity, insulin secretion, and abdominal adiposity in patients with inflammatory rheumatologic disease. Diabetes Care. 2013;36(9):2822-9.

107. Rekedal LR, Massarotti E, Garg R, Bhatia R, Gleeson $\mathrm{T}$, Lu B, et al. Changes in glycosylated hemoglobin after initiation of hydroxychloroquine or methotrexate treatment in diabetes patients with rheumatic diseases. Arthritis Rheum. 2010;62(12): 3569-73.

108. Solomon DH, Massarotti E, Garg R, Liu J, Canning C, Schneeweiss S. Association between diseasemodifying antirheumatic drugs and diabetes risk in patients with rheumatoid arthritis and psoriasis. JAMA. 2011;305(24):2525-31.

109. Dehpouri T, Rokni GR, Narenjbon NA, Goldust M, Yamauchi PS, Wollina U, et al. Evaluation of the glycemic effect of methotrexate in psoriatic arthritis patients with metabolic syndrome: a pilot study. Dermatol Rep. 2019;11(1).

110. Montaudié H, Sbidian E, Paul C, Maza A, Gallini A, Aractingi S, et al. Methotrexate in psoriasis: a systematic review of treatment modalities, incidence, risk factors and monitoring of liver toxicity. J Eur Acad Dermatol Venereol. 2011;25:12-8.

111. Paul C, Cather J, Gooderham M, Poulin Y, Mrowietz U, Ferrandiz C, et al. Efficacy and safety of apremilast, an oral phosphodiesterase 4 inhibitor, in 
patients with moderate-to-severe plaque psoriasis over 52 weeks: a phase III, randomized controlled trial (ESTEEM 2). Br J Dermatol. 2015;173(6): 1387-99.

112. Papp K, Reich K, Leonardi CL, Kircik L, Chimenti S, Langley RGB, et al. Apremilast, an oral phosphodiesterase 4 (PDE4) inhibitor, in patients with moderate to severe plaque psoriasis: results of a phase III, randomized, controlled trial (Efficacy and Safety Trial Evaluating the Effects of Apremilast in Psoriasis [ESTEEM] 1). J Am Acad Dermatol. 2015;73(1): 37-49.

113. da Silva BSP, Bonfá E, de Moraes JCB, Saad CGS, de Medeiros Ribeiro AC, Gonçalves CR, et al. Effects of anti-TNF therapy on glucose metabolism in patients with ankylosing spondylitis, psoriatic arthritis or juvenile idiopathic arthritis. Biologicals. 2010;38(5): 567-9.

114. Kimball AB, Bensimon AG, Guerin A, Yu AP, Wu $\mathrm{EQ}$, Okun MM, et al. Efficacy and safety of adalimumab among patients with moderate to severe psoriasis with co-morbidities: Subanalysis of results from a randomized, double-blind, placebo-controlled, phase III trial. Am J Clin Dermatol. 2011;12(1):51-62.

115. Shao S, He F, Yang Y, Yuan G, Zhang M, Yu X. Th17 cells in type 1 diabetes. Cell Immunol. 2012;280(1): $16-21$.

116. Egeberg A, Wu JJ, Korman N, Solomon JA, Goldblum $\mathrm{O}$, Zhao F, et al. Ixekizumab treatment shows a neutral impact on cardiovascular parameters in patients with moderate-to-severe plaque psoriasis: Results from UNCOVER-1, UNCOVER-2, and UNCOVER-3. J Am Acad Dermatol. 2018;79(1): 104-9.

117. Gerdes S, Pinter A, Papavassilis C, Reinhardt M. Effects of secukinumab on metabolic and liver parameters in plaque psoriasis patients. J Eur Acad Dermatol Venereol. 2020;34(3):533-41.

118. Ng CY, Huang Y-H, Tzeng IS, Liu S-H, Chang Y-C. Changes in metabolic parameters in psoriasis patients treated with interleukin-12/23 blockade (ustekinumab). Dermatol Sin. 2020;38(3):166.

119. Chen SK, Lee H, Jin Y, Liu J, Kim SC. Use of biologic or targeted-synthetic disease-modifying anti-rheumatic drugs and risk of diabetes treatment intensification in patients with rheumatoid arthritis and diabetes mellitus. Rheumatol Adv Pract. 2020;4(2): rkaa027.

120. Guido N, Cices A, Ibler E, Huynh T, Majewski S, Sable K, et al. Multiple sclerosis association with psoriasis: a large US population, single centre, retrospective cross-sectional study. J Eur Acad Dermatol Venereol JEADV. 2017;31(9):e397-8.

121. Edwards LJ, Constantinescu CS. A prospective study of conditions associated with multiple sclerosis in a cohort of 658 consecutive outpatients attending a multiple sclerosis clinic. Mult Scler J. 2004;10(5): 575-81.

122. Kunchok A, Aksamit AJ, Davis JM, Kantarci OH, Keegan BM, Pittock SJ, et al. Association between tumor necrosis factor inhibitor exposure and inflammatory central nervous system events. JAMA Neurol. 2020;77(8):937-46.

123. Fragoso YD, Brooks JBB. Leflunomide and teriflunomide: altering the metabolism of pyrimidines for the treatment of autoimmune diseases. Expert Rev Clin Pharmacol. 2015;8(3):315-20.

124. Gray O, McDonnell GV, Forbes RB. Methotrexate for multiple sclerosis. Cochrane Database Syst Rev. $2004 ;(2)$.

125. Havrdová E, Belova A, Goloborodko A, Tisserant A, Wright A, Wallstroem E, et al. Activity of secukinumab, an anti-IL-17A antibody, on brain lesions in RRMS: results from a randomized, proof-of-concept study. J Neurol. 2016;263(7):1287-95.

126. Segal BM, Constantinescu CS, Raychaudhuri A, Kim L, Fidelus-Gort R, Kasper LH, et al. Repeated subcutaneous injections of IL12/23 p40 neutralising antibody, ustekinumab, in patients with relapsingremitting multiple sclerosis: a phase II, doubleblind, placebo-controlled, randomised, dose-ranging study. Lancet Neurol. 2008;7(9):796-804.

127. Wilson FC, Icen M, Crowson CS, McEvoy MT, Gabriel SE, Kremers HM. Incidence and clinical predictors of psoriatic arthritis in patients with psoriasis: a population-based study. Arthritis Rheum. 2009;61(2):233-9.

128. Menter A. Psoriasis and psoriatic arthritis overview. Am J Manag Care. 2016;22(8 Suppl):s216-24.

129. Ocampo DV, Gladman D. Psoriatic arthritis. F1000Res. 2019;8:F1000 Faculty Rev-65.

130. Menter A, Gelfand JM, Connor C, Armstrong AW, Cordoro KM, Davis DMR, et al. Joint American Academy of Dermatology-National Psoriasis Foundation guidelines of care for the management of psoriasis with systemic nonbiologic therapies. J Am Acad Dermatol. 2020;82(6):1445-86.

131. Singh JA, Guyatt G, Ogdie A, Gladman DD, Deal C, Deodhar A, et al. Special article: 2018 American College of Rheumatology/National Psoriasis Foundation Guideline for the Treatment of Psoriatic 
Arthritis. Arthritis Care Res (Hoboken). 2019;71(1): 2-29.

132. Merola JF, Elewski B, Tatulych S, Lan S, Tallman A, Kaur M. Efficacy of tofacitinib for the treatment of nail psoriasis: two 52-week, randomized, controlled phase 3 studies in patients with moderate-to-severe plaque psoriasis. J Am Acad Dermatol. 2017;77(1): 79-87.

133. Menter A, Strober BE, Kaplan DH, Kivelevitch D, Prater EF, Stoff B, et al. Joint AAD-NPF guidelines of care for the management and treatment of psoriasis with biologics. J Am Acad Dermatol. 2019;80(4): 1029-72.

134. Deodhar A, Helliwell PS, Boehncke W-H, Kollmeier AP, Hsia EC, Subramanian RA, et al. Guselkumab in patients with active psoriatic arthritis who were biologic-naive or had previously received $\mathrm{TNF} \alpha$ inhibitor treatment (DISCOVER-1): a double-blind, randomised, placebo-controlled phase 3 trial. The Lancet. 2020;395(10230):1115-25.

135. Makredes M, Robinson D Jr, Bala M, Kimball AB. The burden of autoimmune disease: a comparison of prevalence ratios in patients with psoriatic arthritis and psoriasis. J Am Acad Dermatol. 2009;61(3):405-10.

136. Lichtenstein GR, Loftus EV, Isaacs KL, Regueiro MD, Gerson LB, Sands BE. ACG clinical guideline: management of Crohn's disease in adults. Off J Am Coll Gastroenterol ACG. 2018;113(4).

137. Varkas G, Thevissen K, De Brabanter G, Van Praet L, Czul-Gurdian F, Cypers $\mathrm{H}$, et al. An induction or flare of arthritis and/or sacroiliitis by vedolizumab in inflammatory bowel disease: a case series. Ann Rheum Dis. 2017;76(5):878-81.

138. Rubin DT, Ananthakrishnan AN, Siegel CA, Sauer BG, Long MD. ACG clinical guideline: ulcerative colitis in adults. Off J Am Coll Gastroenterol ACG. 2019;114(3).

139. Rogler G. Efficacy of JAK inhibitors in Crohn's Disease. J Crohn's Colitis. 2019;14(Supplement_2): S746-54.

140. Sands BE, Sandborn WJ, Panaccione R, O'Brien CD, Zhang $\mathrm{H}$, Johanns J, et al. Ustekinumab as induction and maintenance therapy for ulcerative colitis. N Engl J Med. 2019;381(13):1201-14.

141. Fieldhouse KA, Ukaibe S, Crowley EL, Khanna R, O'Toole A, Gooderham MJ. Inflammatory bowel disease in patients with psoriasis treated with interleukin-17 inhibitors. Drugs Context. 2020;9.

142. Schreiber S, Colombel J-F, Feagan BG, Reich K, Deodhar AA, McInnes IB, et al. Incidence rates of inflammatory bowel disease in patients with psoriasis, psoriatic arthritis and ankylosing spondylitis treated with secukinumab: a retrospective analysis of pooled data from 21 clinical trials. Ann Rheum Dis. 2019;78(4):473-9.

143. Paiva ES, Macaluso DC, Edwards A, Rosenbaum JT. Characterisation of uveitis in patients with psoriatic arthritis. Ann Rheum Dis. 2000;59(1):67-70.

144. Zeboulon N, Dougados M, Gossec L. Prevalence and characteristics of uveitis in the spondyloarthropathies: a systematic literature review. Ann Rheum Dis. 2008;67(7):955-9.

145. Charlton R, Green A, Shaddick G, Snowball J, Nightingale A, Tillett W, et al. Risk of uveitis and inflammatory bowel disease in people with psoriatic arthritis: a population-based cohort study. Ann Rheum Dis. 2018;77(2):277-80.

146. Lambert JR, Wright V. Eye inflammation in psoriatic arthritis. Ann Rheum Dis. 1976;35(4):354-6.

147. Gómez-Gómez A, Loza E, Rosario MP, Espinosa G, de Morales JMGR, Herreras JM, et al. Efficacy and safety of immunomodulatory drugs in patients with anterior uveitis: a systematic literature review. Medicine. 2017;96(42).

148. Zu Hoerste MM, Walscheid K, Tappeiner C, ZurekImhoff B, Heinz C, Heiligenhaus A. The effect of methotrexate and sulfasalazine on the course of HLA-B27-positive anterior uveitis: results from a retrospective cohort study. Graefes Arch Clin Exp Ophthalmol. 2018;256(10):1985-92.

149. Sheppard J, Joshi A, Betts KA, Hudgens S, Tari S, Chen $\mathrm{N}$, et al. Effect of adalimumab on visual functioning in patients with noninfectious intermediate uveitis, posterior uveitis, and panuveitis in the VISUAL-1 and VISUAL-2 trials. JAMA Ophthalmol. 2017;135(6):511-8.

150. Ardoin SP, Kredich D, Rabinovich E, Schanberg LE, Jaffe GJ. Infliximab to treat chronic noninfectious uveitis in children: retrospective case series with long-term follow-up. Am J Ophthalmol. 2007;144(6):844-9.

151. Smith JA, Thompson DJS, Whitcup SM, Suhler E, Clarke G, Smith S, et al. A randomized, placebocontrolled, double-masked clinical trial of etanercept for the treatment of uveitis associated with juvenile idiopathic arthritis. Arthritis Care Res. 2005;53(1):18-23.

152. Rudwaleit M, Rosenbaum JT, Landewé R, MarzoOrtega H, Sieper J, Van Der Heijde D, et al. Observed incidence of uveitis following certolizumab pegol treatment in patients with axial spondyloarthritis. Arthritis Care Res. 2016;68(6):838-44. 
153. Deodhar AA, Miceli-Richard C, Baraliakos X, MarzoOrtega H, Gladman DD, Blanco R, et al. Incidence of uveitis in secukinumab-treated patients with ankylosing spondylitis: pooled data analysis from three phase 3 studies. ACR Open Rheumatol. 2020;2(5):294-9.

154. Mugheddu C, Atzori L, Del Piano M, Lappi A, Pau M, Murgia $S$, et al. Successful ustekinumab treatment of noninfectious uveitis and concomitant severe psoriatic arthritis and plaque psoriasis. Dermatol Therapy. 2017;30(5):e12527.

155. Chateau T, Angioi K, Peyrin-Biroulet L. Two cases of successful ustekinumab treatment for non-infectious uveitis associated with Crohn's disease. J Crohn's Colitis. 2020;14(4):571.

156. Watanabe K, Takase K, Ohno S, Ideguchi H, Nozaki A, Ishigatsubo Y. Reactivation of hepatitis B virus in a hepatitis B surface antigen-negative patient with rheumatoid arthritis treated with methotrexate. Mod Rheumatol. 2012;22(3):470-3.

157. Perrillo RP, Gish R, Falck-Ytter YT. American Gastroenterological Association Institute technical review on prevention and treatment of hepatitis $B$ virus reactivation during immunosuppressive drug therapy. Gastroenterology. 2015;148(1):221-44.

158. Maurer TA, Zackheim HS, Tuffaneli L, Berger TG. The use of methotrexate for treatment of psoriasis in patients with HIV infection. J Am Acad Dermatol. 1994;31(2):372-5.

159. Binymin K, Cooper RG. Late reactivation of spinal tuberculosis by low-dose methotrexate therapy in a patient with rheumatoid arthritis. Rheumatology. 2001;40(3):341-2.

160. Chyuan IT, Hsu P-N. Tumor necrosis factor: the key to hepatitis B viral clearance. Cell Mol Immunol. 2018;15(8):731-3.

161. Cantini F, Boccia S, Goletti D, Iannone F, Leoncini $\mathrm{E}$, Panic N, et al. HBV reactivation in patients treated with antitumor necrosis factor-alpha (TNF- $\alpha$ ) agents for rheumatic and dermatologic conditions: a systematic review and meta-analysis. Int $\mathrm{J}$ Rheumatol. 2014.

162. Caso F, Cantarini L, Morisco F, Del Puente A, Ramonda R, Fiocco U, et al. Current evidence in the field of the management with TNF- $\alpha$ inhibitors in psoriatic arthritis and concomitant hepatitis $C$ virus infection. Expert Opin Biol Ther. 2015;15(5): 641-50.

163. Abuchar A, Vitiello M, Kerdel FA. Psoriasis treated with ustekinumab in a patient with hepatitis C. Int J Dermatol. 2013;52(3):381-2.
164. Chiu HY, Chen CH, Wu MS, Cheng YP, Tsai TF. The safety profile of ustekinumab in the treatment of patients with psoriasis and concurrent hepatitis B or C. Br J Dermatol. 2013;169(6):1295-303.

165. Akiyama S, Cotter TG, Sakuraba A. Risk of hepatitis $B$ virus reactivation in patients with autoimmune diseases undergoing non-tumor necrosis factor-targeted biologics. World J Gastroenterol. 2021;27(19): 2312.

166. Duncan JR, Orlowski TJ, Elewski BE. Safety of guselkumab in hepatitis B virus infection. Dermatol Online J. 2019;25(10).

167. Carmona L, Gómez-Reino JJ, Rodríguez-Valverde V, Montero D, Pascual-Gómez E, Mola EM, et al. Effectiveness of recommendations to prevent reactivation of latent tuberculosis infection in patients treated with tumor necrosis factor antagonists. Arthritis Rheum. 2005;52(6):1766-72.

168. Blauvelt A. Safety of secukinumab in the treatment of psoriasis. Expert Opin Drug Saf. 2016;15(10): $1413-20$

169. Fowler E, Ghamrawi RI, Ghiam N, Liao W, Wu JJ. Risk of tuberculosis reactivation during interleukin17 inhibitor therapy for psoriasis: a systematic review. J Eur Acad Dermatol Venereol. 2020;34(7): 1449-56.

170. Puig L, Tsai TF, Bhutani T, Uy J, Ramachandran P, Song $\mathrm{M}$, et al. Safety in moderate-to-severe plaque psoriasis patients with latent tuberculosis treated with guselkumab and anti-tuberculosis treatments concomitantly: results from pooled phase 3 VOYAGE 1 \& VOYAGE 2 trials. J Eur Acad Dermatol Venereol. 2020;34(8):1744-9.

171. McDonough E, Ayearst R, Eder L, Chandran V, Rosen CF, Thavaneswaran A, et al. Depression and anxiety in psoriatic disease: prevalence and associated factors. J Rheumatol. 2014;41(5):887-96.

172. Kamalaraj N, El-Haddad C, Hay P, Pile K. Systematic review of depression and anxiety in psoriatic arthritis. Int J Rheum Dis. 2019;22(6):967-73.

173. Michelsen B, Kristianslund EK, Sexton J, Hammer $\mathrm{HB}$, Fagerli KM, Lie E, et al. Do depression and anxiety reduce the likelihood of remission in rheumatoid arthritis and psoriatic arthritis? Data from the prospective multicentre NOR-DMARD study. Ann Rheum Dis. 2017;76(11):1906-10.

174. Betteridge N, Boehncke WH, Bundy C, Gossec L, Gratacós J, Augustin M. Promoting patient-centred care in psoriatic arthritis: a multidisciplinary European perspective on improving the patient experience. J Eur Acad Dermatol Venereol. 2016;30(4): 576-85. 
175. Lebwohl MG, Papp KA, Marangell LB, Koo J, Blauvelt $A$, Gooderham $M$, et al. Psychiatric adverse events during treatment with brodalumab: analysis of psoriasis clinical trials. J Am Acad Dermatol. 2018;78(1):81-9.e5.

176. Hashim PW, Chen T, Lebwohl MG, Marangell LB, Kircik LH. What lies beneath the face value of a BOX WARNING: a deeper look at brodalumab. J Drugs Dermatol. 2018;17(8):s29-34.

177. Brenner $\mathrm{P}$, Citarella $\mathrm{A}$, Wingård L, Sundström A. Use of antidepressants and benzodiazepine-related hypnotics before and after initiation of TNF- $\alpha$ inhibitors or non-biological systemic treatment in patients with rheumatoid arthritis, psoriatic arthritis or ankylosing spondylitis. BMC Rheumatol. 2020;4(1):9.

178. Fleming $\mathrm{P}$, Roubille $\mathrm{C}$, Richer $\mathrm{V}$, Starnino $\mathrm{T}$, McCourt C, McFarlane A, et al. Effect of biologics on depressive symptoms in patients with psoriasis: a systematic review. J Eur Acad Dermatol Venereol. 2015;29(6):1063-70.

179. Wu C-Y, Chang Y-T, Juan C-K, Shen J-L, Lin Y-P, Shieh J-J, et al. Depression and insomnia in patients with psoriasis and psoriatic arthritis taking tumor necrosis factor antagonists. Medicine. 2016;95(22).

180. Deodhar A, Mease PJ, McInnes IB, Baraliakos X, Reich K, Blauvelt A, et al. Long-term safety of secukinumab in patients with moderate-to-severe plaque psoriasis, psoriatic arthritis, and ankylosing spondylitis: integrated pooled clinical trial and post-marketing surveillance data. Arthritis Res Ther. 2019;21(1):1-11.

181. Karmacharya P, Crowson CS, Bekele D, Achenbach SJ, Davis JM, III, Ogdie A, et al. The epidemiology of psoriatic arthritis over 5 decades: a populationbased study. Arthritis Rheumatol. 2021.

182. Meissner Y, Rudi T, Fischer-Betz R, Strangfeld A. Pregnancy in women with psoriatic arthritis: a systematic literature review of disease activity and adverse pregnancy outcomes. Semin Arthritis Rheum. 2021;51(3):530-8.

183. Hamroun S, Hamroun A, Bigna J-J, Allado E, Förger F, Molto A. Fertility and pregnancy outcomes in women with spondyloarthritis: a systematic review and meta-analysis. Rheumatology. 2021.
184. Smith CJF, Bandoli G, Kavanaugh A, Chambers CD. Birth outcomes and disease activity during pregnancy in a prospective cohort of women with psoriatic arthritis and ankylosing spondylitis. Arthritis Care Res (Hoboken). 2020;72(7):1029-37.

185. Sammaritano LR, Bermas BL, Chakravarty EE, Chambers C, Clowse MEB, Lockshin MD, et al. 2020 American College of Rheumatology Guideline for the management of reproductive health in rheumatic and musculoskeletal diseases. Arthritis Rheumatol. 2020;72(4):529-56.

186. Götestam Skorpen C, Hoeltzenbein M, Tincani A, Fischer-Betz R, Elefant E, Chambers C, et al. The EULAR points to consider for use of antirheumatic drugs before pregnancy, and during pregnancy and lactation. Ann Rheum Dis. 2016;75(5):795.

187. Berman M, Zisman D, Wollman J, Levartovsky D, Rimon E, Elkayam O, et al. The effect of pregnancy on disease activity in patients with psoriatic arthritis. J Rheumatol. 2018;45(12):1651-5.

188. Polachek A, Polachek Shlomi I, Spitzer K, Pereira D, Ye JY, Chandran V, et al. Outcome of pregnancy in women with psoriatic arthritis compared to healthy controls. Clin Rheumatol. 2019;38(3):895-902.

189. Eudy AM, McDaniel G, Clowse ME. Pregnancy outcomes, fertility, and family planning in women with psoriatic arthritis. Obstet Med. 2020;13(2): 70-5.

190. Lloyd ME, Carr M, McElhatton P, Hall GM, Hughes RA. The effects of methotrexate on pregnancy, fertility and lactation. QJM Int J Med. 1999;92(10): 551-63.

191. Gutierrez JC, Hwang K. The toxicity of methotrexate in male fertility and paternal teratogenicity. Expert Opin Drug Metab Toxicol. 2017;13(1):51-8.

192. Leroy C, Rigot J-M, Leroy M, Decanter C, Le Mapihan $\mathrm{K}$, Parent A-S, et al. Immunosuppressive drugs and fertility. Orphanet J Rare Dis. 2015;10(1):136.

193. Bazzani C, Andreoli L, Agosti M, Nalli C, Tincani A. Antirheumatic drugs and reproduction in women and men with chronic arthritis. RMD Open. 2015;1(Suppl 1):e000048. 